\title{
Determination of sediment quality in the Nyl River system, Limpopo Province, South Africa
}

\author{
R Greenfield*, JHJ van Vuren and V Wepener \\ University of Johannesburg APK, PO Box 524, Auckland Park 2006, South Africa
}

\begin{abstract}
The importance of wetland management and conservation is becoming more and more prevalent in the world today. It is thus important to determine baseline contamination values for wetlands to assist in making informed management decisions. Sediment from the Nyl River flood plain in the dry Limpopo Province was analysed using sequential extraction and ICP-MS to determine baseline metal concentrations, and bioavailability thereof. Eight heavy metal $(\mathrm{Cu}, \mathrm{Cd}, \mathrm{Cr}, \mathrm{Al}, \mathrm{As}, \mathrm{Zn}, \mathrm{Mn}, \mathrm{Pb})$ concentrations were determined and compared to sediment quality guideline values to assess sediment quality. Fractionation of the elements was also noted to assess the bioavailability of the metals. The results indicated that the sediment is of a fair quality in comparison to the sediment quality guideline values. They also indicate that the metals will only become available in the presence of strong reducing agents as most of the metal concentrations were recorded in the $4^{\text {th }}$ and $5^{\text {th }}$ fractions obtained from the Tessier sequential extraction of the sediment samples. The study concluded that the sediment is of a fair quality and that it poses little potential threat to the system.
\end{abstract}

Keywords: sequential extraction, Nylsvley, wetlands, sediment quality, metals

\section{Introduction}

From the myriad results reported in the literature it is possible to conclude that metals have a high toxicity and worldwide distribution in the aquatic environment. They are also known to accumulate in sediments (Klavins et al., 1998) Data concerning environmental effects of chemicals clearly indicate the accelerated and negative effects of the dispersal of metals and metalloids in the environment by anthropogenic activities, and the changes made to global chemical cycles (Mester et al., 1998). The study of sediments in wetlands is important as wetlands act as natural filters for water in a system and thus act as a sink for contaminated suspended particles in the water column. Sediments also provide an indication of potential contamination on a temporal scale. The analysis of water indicates the contamination status at present whereas sediment can provide information on the systems' contamination history (Shine, 2004). Wetlands can also act as a source of increased contaminant levels in a water body during periods of increased water flow by remobilising the settled particles resulting in the re-suspension of the contaminants into the water. These sediments are transported downstream and affect the ecosystems of the river downstream as well as flooded wetlands (Ulbrich et al., 1997). The mobilisation of sediments by water flow allows contaminants to penetrate deep into wetlands by flood waters (Ulbrich et al., 1997). It is thus important to assess the sediment quality throughout the system.

Contaminants bind to the sediment particles (Buykx et al., 2002). These contaminants can be either metal compounds, or originate from chemical compounds released into the system via a number of anthropogenic activities.

These metal compounds may be present in several geochemical phases that act as reservoirs or sinks of trace metals in the

\footnotetext{
* To whom all correspondence should be addressed.

觉 +2711 489 2444; fax: +2711 489 2286;

e-mail: rgreenfield@uj.ac.za

Received 23 January 2007; accepted in revised form 31 July 2007.
}

environment ( $\mathrm{Li}$ et al., 1995). These phases include the broad categories: exchangeable, specifically adsorbed, carbonate, FeMn oxides, organic matter and mineral lattice (Li et al., 1995).It is thus recognised that the quantification of the chemical forms of metals in the sediment is essential for estimating the mobility and bioavailability of metals in the environment (Leschber et al., 1985; Li et al., 1995).

The study area falls within the Waterberg catchment area. It follows the course of both the Klein and Groot Nyl Rivers, from their sources to their confluence, and then the course of the Nyl River to Moorddrift Dam near Mokopane (Potgietersrus). The Nyl River flows through or is impacted on by the towns of Modimolle (Nylstroom) and Moogkopong (Naboomspruit). The Nyl River flows in a north-easterly direction from Modimolle in the west to Mokopane in the east. At Mokopane the river changes course northwards and is renamed the Makgalakwena River. The Makgalakwena River then flows into the Limpopo River. The Nyl River and its flood plain are subjected to various potential impacts via anthropogenic activities, such as mining and farming, as well as the associated problems caused by formal and informal settlements. According to the Mookgopong (Anon, 2003a) and Mokopane (Anon, 2003b) tourism bureau the farming activities that take place include both agriculture and livestock. Crops such as maize, groundnuts, tobacco, citrus, cotton, millet, wheat, rice and sunflowers are planted in the fertile soil of the Waterberg catchment area. Cattle are also farmed extensively in the rich grazing provided by the flood plain. Around the sources of the Klein Nyl River and the Groot Nyl River game farming takes place on a large scale with a large number of privately owned game farms (Anon, 2003c). The mining of tin, chrome and fluorspar also takes place in the area between Mookgopong and Mokopane. The Waterberg catchment is characterised by its richness in minerals with 545 known mineral deposits (Anon, 2003d).

The Nyl River flood plain is South Africa's largest ephemeral wetland, being 24250 ha in size, and 500 ha of this wetland is situated in a nature reserve and is classified as a RAM- 
SAR site. The flood plain is unique in the fact that it is the only place in South Africa where the wild rice Oryza longistaminata grows (Gibbs et al., 1991). The nature reserve also provides valuable breeding ground for the endangered Roan antelope (Hippotragus equinus) and numerous waterfowl species. In all there are 23 Red Data bird species found in the wetland (Tarboton, 1987).

\section{Materials and methods}

The 18 sampling sites were chosen to be evenly distributed throughout the system, thereby providing representative sample points in the Nyl River, the Nyl River flood plain and some of the tributaries with more permanent flow throughout the season. Figure 1 indicates a schematic representation of the study area and sampling points. These sites were selected so that possible point sources of pollution could be identified.

It is generally recognised that information about the physico-chemical forms of elements is necessary to understand their environmental behaviour such as mobility and bioavailability (Tack and Verloo, 1995). Sediment samples were collected from the 18 localities throughout the system and subjected to a 5 -point sequential extraction. The sequential extraction of metals from solid media is a common tool used in the analysis of environmental geochemistry (Sutherland and Tack, 2003). This process uses different reducing and oxidising agents to remove each fraction of the bound metals in the sample. This allows for the evaluation of the total metal content available for uptake by organisms or bioavailability.

The 5 fractions extracted are listed in Table 1 with a brief explanation of the remobilisation of metal ions from each fraction.

Sediment samples were collected quarterly from March 2001 to July 2002 from the upper $50 \mathrm{~mm}$ of the substrate and placed in $350 \mathrm{~m} \ell$ plastic honey jars and frozen. Frozen samples were returned to the laboratory for further analysis.

In the laboratory the sediment samples underwent a process of sequential extraction. It was decided to use a 5-fraction extraction, which identifies the non-residual metal concentrations among the three basic operationally-defined host fractions (Ngiam and Lim, 2000). The process followed was modified

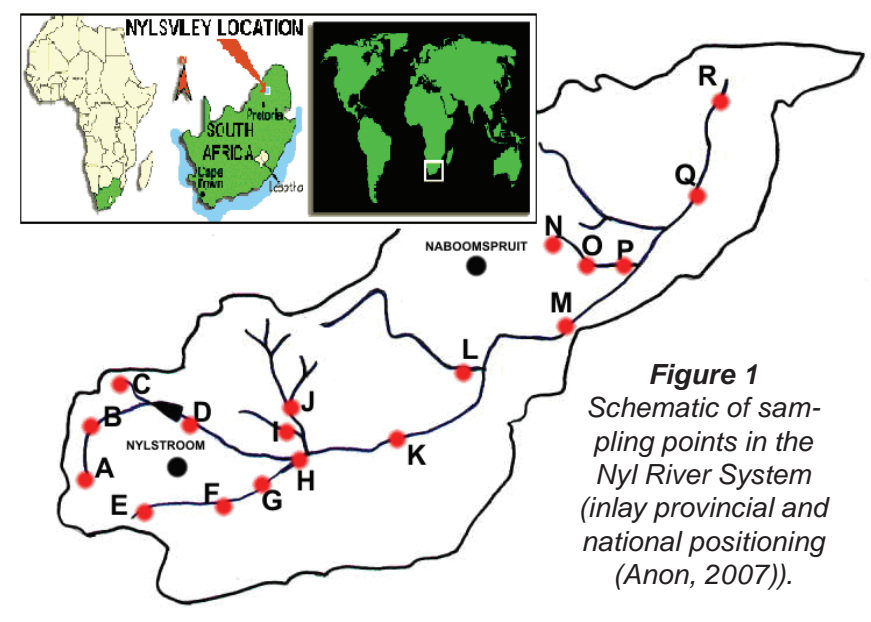

from the process set out by Tessier et al. (1979). The process involves subjecting the sediment samples to chemicals of decreasing $\mathrm{pH}$ and increasing oxidising strength, to remove the operationally defined host fractions corresponding to the exchangeable, carbonate, reducible and organic/sulphide phases (Ngiam and Lim, 2000). Sediment samples were dried in an oven at $60^{\circ} \mathrm{C}$. Approximately $1 \mathrm{~g}$ of dry sample was placed in a $50 \mathrm{~m} \ell$ nalgene polyethylene centrifuge tube before it underwent extraction. Figure 2 gives a brief outline of the process followed during the extraction process. Two replicates were prepared for each extraction.

All samples were then analysed for metal content using standard inductively coupled plasma mass spectrophotometry (ICP-MS) techniques. ICP-MS analyses were carried out on an X-series thermo elemental quadrupole-based ICP-MS. Yttrium was used as an internal standard to correct for high dissolved solids arising from matrix effects. The metals chosen for the study were selected from a list of metals that were above acceptable levels in a scan done on water from the system.

For statistical analysis metal concentrations in sediment fractions were analysed using one-way ANOVA with season and site as independent factors. Significance level was taken as $\mathrm{P}<0.05$.

\begin{tabular}{|l|l|l|l|}
\hline \multicolumn{2}{|c|}{ Table of the different fractions extracted during the sequential extraction process, their binding sites } \\
and the remobilisation thereof (adapted from Coetzee, 1993)
\end{tabular}




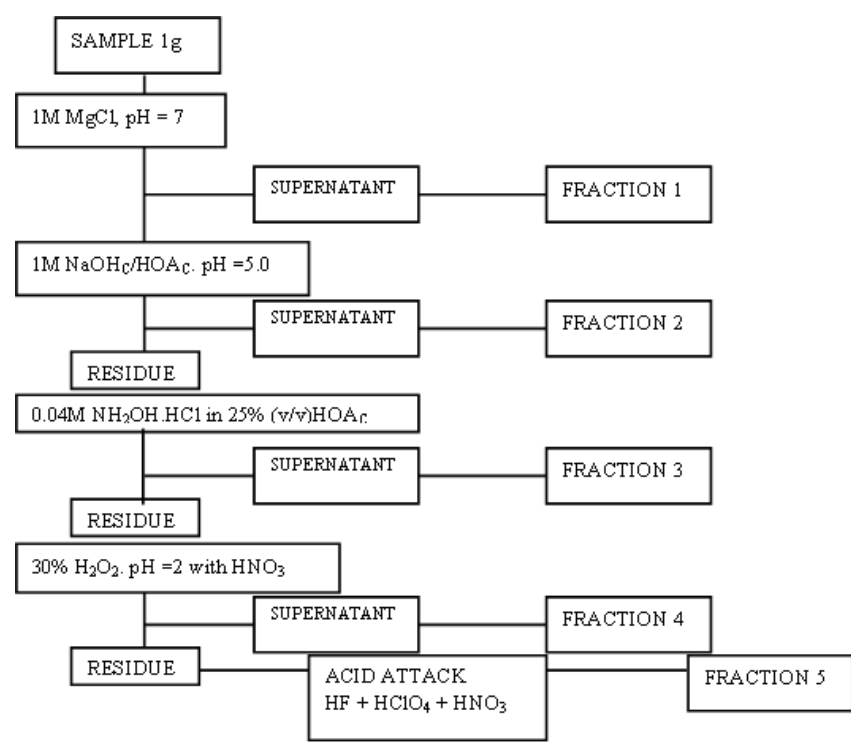

Figure 2

Flow diagram for Tessier sequential extraction (Coetzee, 1993)

\section{Results and discussion}

\section{Aluminium}

The increased bioavailability of aluminium in sediments comes about by the remobilisation of sediment particles by increased water flow and agitation in conjunction with decrease in $\mathrm{pH}$ (Buykx et al., 2002). This increased bioavailability can have various physiological effects on the organisms in the system.

Figures 3 A to D indicate the various aluminium concentrations, for each fraction, observed at each locality during the different sampling periods. The concentrations recorded indicate that the majority of the aluminium in the sediment is partitioned into the $4^{\text {th }}$ and $5^{\text {th }}$ fractions, that is, they are bound to the fractions containing organic matter and the residual or inert fraction. This would indicate that the aluminium in the sediment is not very bioavailable and will only be released in the presence of a strong reducing agent or if the $\mathrm{pH}$ in the system were to decrease.

No significant differences were found between the mean aluminium concentrations for Fractions 1, 2, 4 and 5, when the fractions for each month were compared to each other. The comparison between mean aluminium concentrations in Fraction 3 for March and July were, however, significantly different $(\mathrm{P}<0.05)$.

The results indicate that the majority of the aluminium is concentrated in the $5^{\text {th }}$ or inert fraction. This further implies that the majority of the aluminium extracted from the sediment is from a lattice or detrital origin and can be regarded as coming from a natural source (Jain, 2004) and that aluminium toxicity is not a threat to the organisms in the system.

\section{Chromium}

Chromium is a relatively scarce metal that occurs in several states. The most toxic of these states is the chromium VI or hexavalent state. Fytianos and Lourantou (2004) observed in their study of sediment from Lake Volvi and Koronia in Northern Greece, that chromium is primarily distributed in the reducible (Fe/Mn oxide), residual and oxidisable fractions. They found that metals bound to these different fractions have different potentials for remobilisation and for uptake by biota (Fytianos and Lourantou, 2004).

Figure 4 indicates the chromium concentrations found in the samples collected during the different sampling months. The graphs illustrate that the chromium is partitioned in the different fraction during the different months. Chromium is predominantly found in the oxidisable Fraction 4 and inert Fraction 5. During the August 2001, November 2001 and March 2002 sampling periods the observed partitioning of chromium concentrations is primarily in Fractions 4 and 5 . During the July sampling the majority of the chromium is found in the $5^{\text {th }}$ fraction.

In the comparison between the different fractions and the months sampled, Fractions 4 and 5 indicated no signifi- a
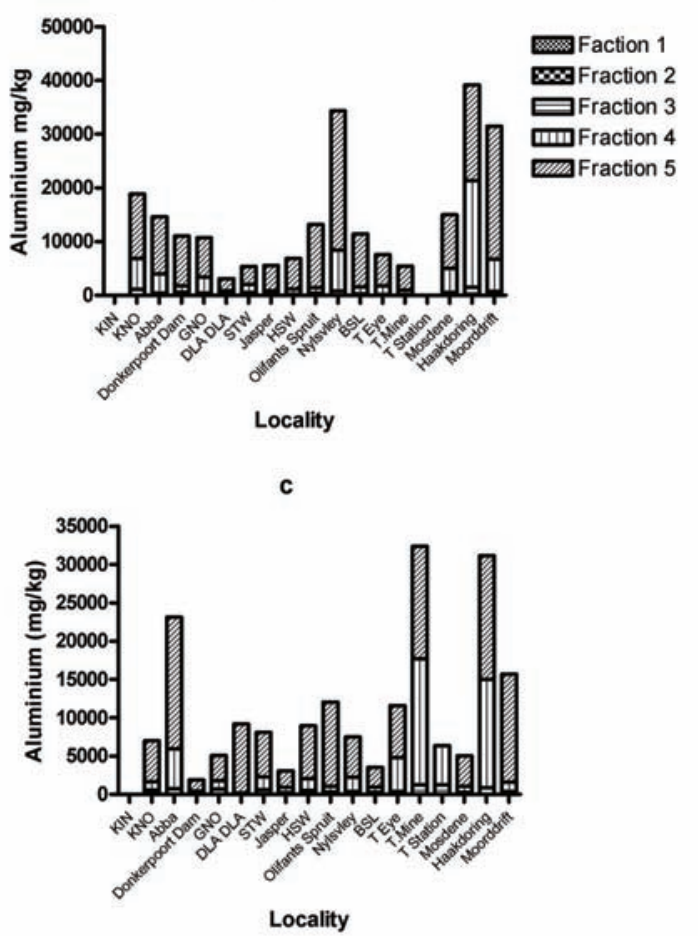

b

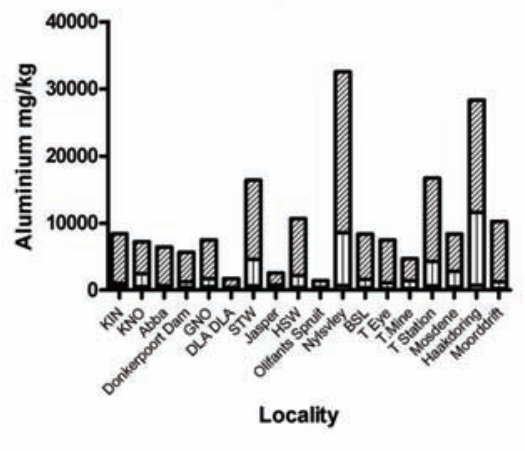

d

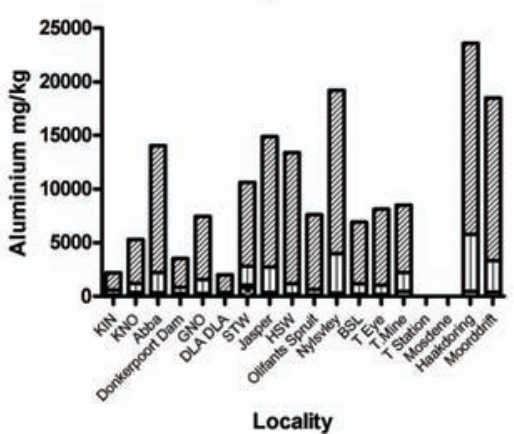




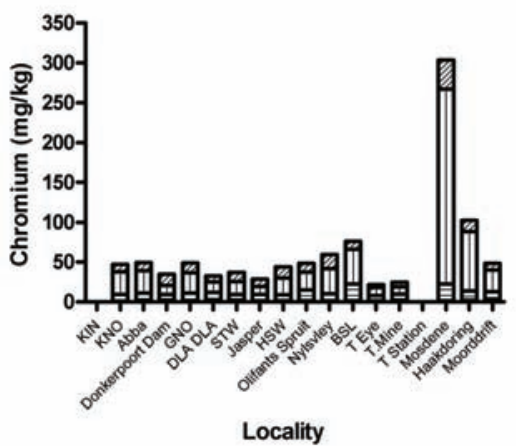

C

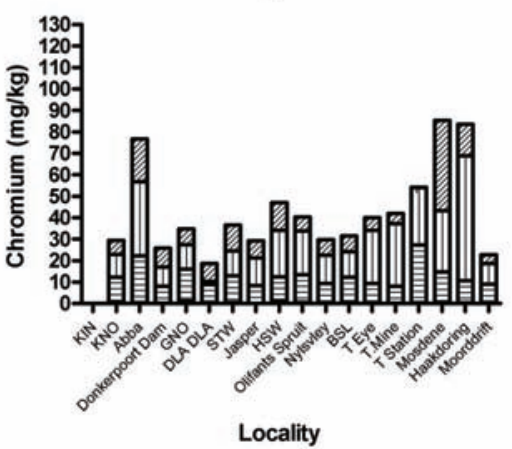

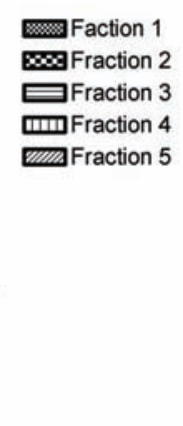

Chromium concentrations $(\mathrm{mg} / \mathrm{kg})$ in the different fractions during the different sampling months. A: August 2001, B: November 2001, C: March 2002, D: July 2002

a

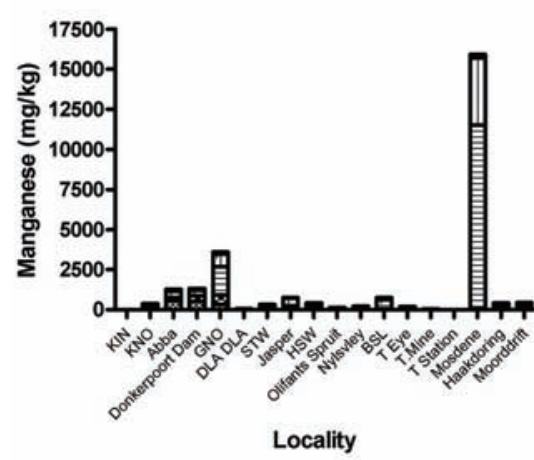

c

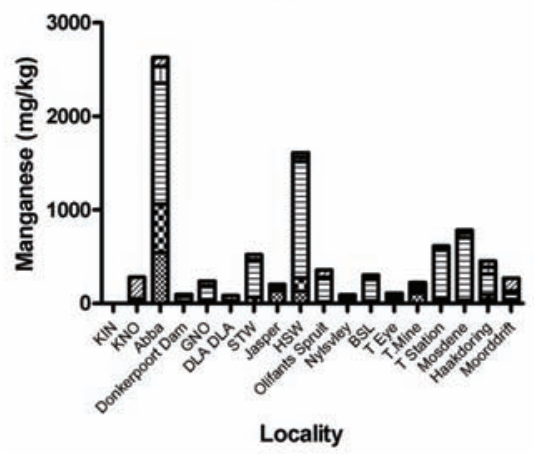

b

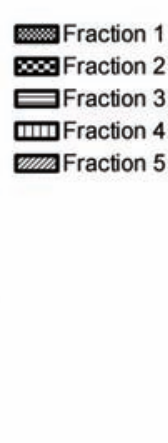

Manganese concentrations $(\mathrm{mg} / \mathrm{kg})$ in the different fractions during the different sampling months. A: August 2001, B: November 2001, C: March 2002, D: July 2002

d

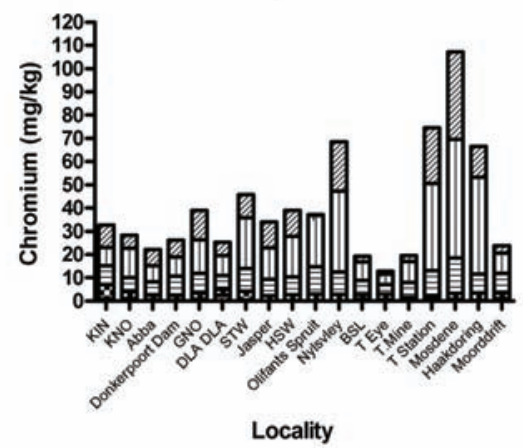

d
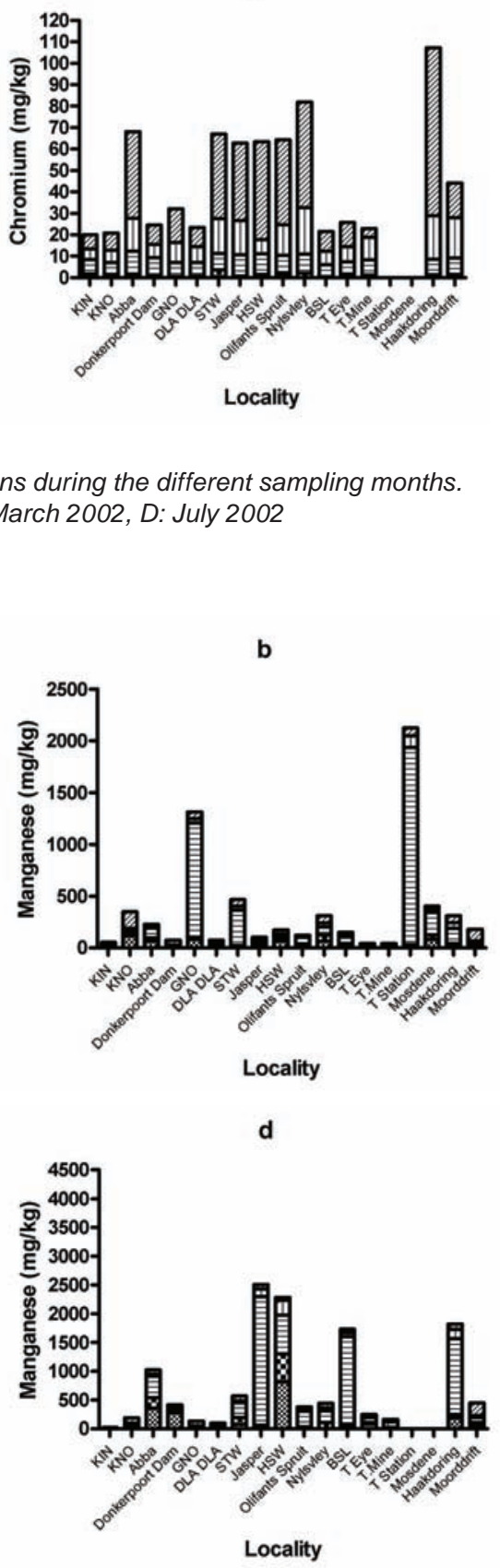
manganese during the sampling period. No significant differences were recorded 
in manganese concentrations between corresponding fractions of each sampling month. This would indicate that manganese could be released into the system if the $\mathrm{pH}$ of the water in the system were to decrease.

\section{Zinc}

Zinc is an essential micronutrient for all organisms and forms the active site for various metalloenzymes (DWAF, 1996). Figure 6 illustrates the zinc concentrations in the system during the sampling period.

There were no significant differences between Fractions 4 and 5 in the mean zinc concentrations during the different sampling months. In Fraction 3 significant differences $(\mathrm{P}<0.05)$ in the mean zinc concentrations were found between August 2001 and July 2002, August 2001 and March 2002, November 2001 and July 2002 and March 2002 and July 2002. Fraction 2 indicated significant differences in the mean zinc concentrations between August 2001 and March 2002 and Fraction 1 between August 2001 and July 2002. The increased levels of zinc measured in July 2002 samples were predominantly found at the sites close to the source of the river and this would thus indicate that increased levels were from a natural source.

\section{Copper}

Copper is a common environmental metal and is essential in cellular metabolism but at high concentrations it can be highly toxic to fish (Grosell et al., 1997). Copper is generally remobilised with acid-base ion exchange or oxidation mechanism (Gomez Ariza et al., 2000).

Figure 7 illustrates the copper concentrations observed in the system during the sampling period. Copper concentrations recorded all

a

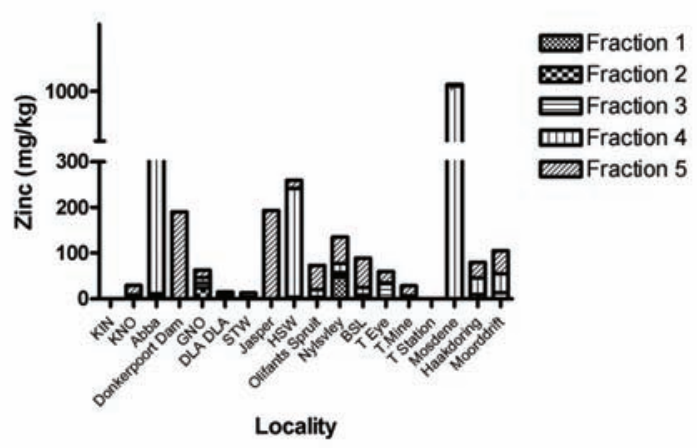

c

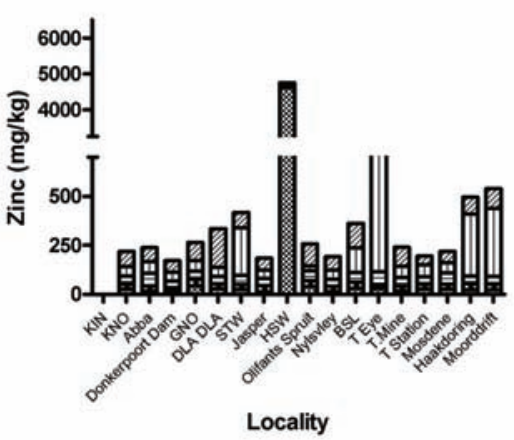

Figure 6(a-d)

Zinc concentrations $(\mathrm{mg} / \mathrm{kg})$ in the different fractions during the different sampling months. A: August 2001, B: November 2001, C: March 2002, D: July 2002
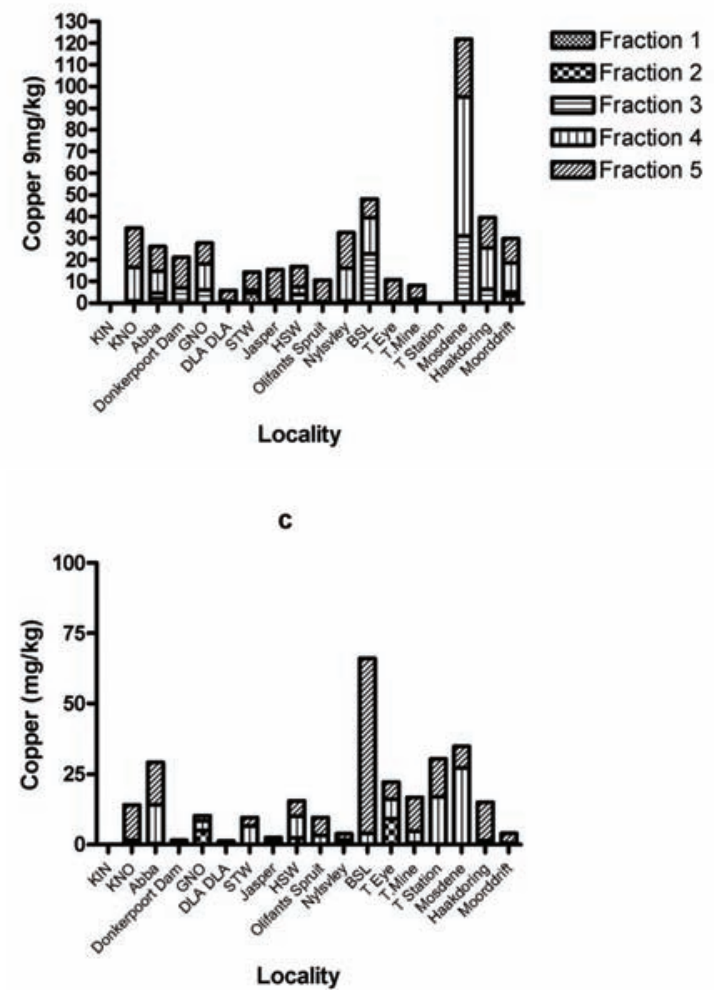

Figure 7(a-d)

Copper concentrations $(\mathrm{mg} / \mathrm{kg})$ in the different fractions during the different sampling months. A: August 2001, B: November 2001, C: March 2002, D: July 2002

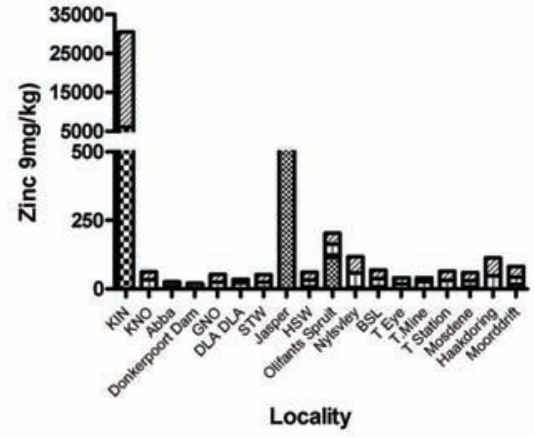

d

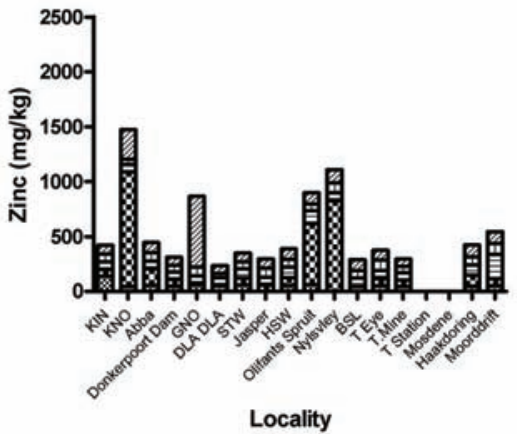




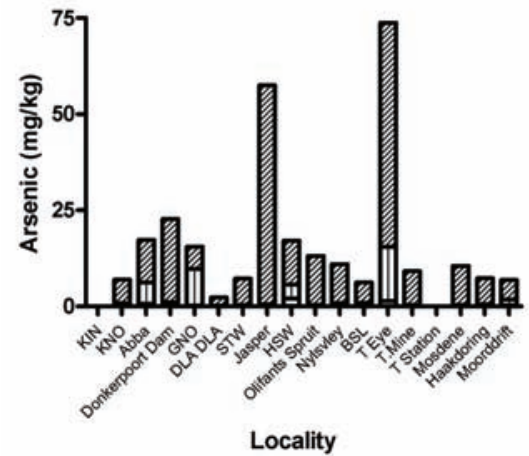

C

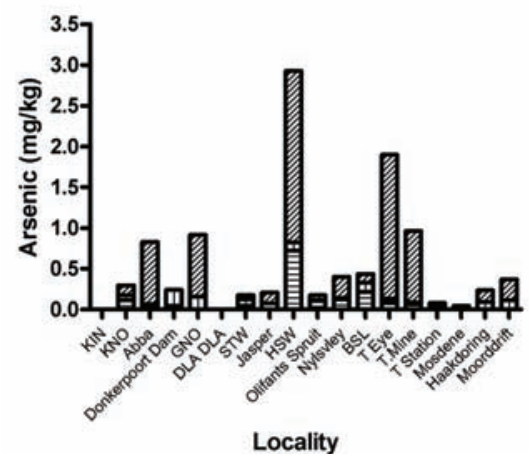

b

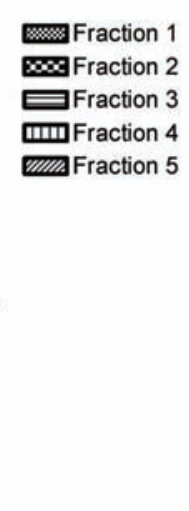

Figure 8(a-d)

Arsenic concentrations $(\mathrm{mg} / \mathrm{kg})$ in the different fractions during the different sampling months. A: August 2001, B: November 2001, C: March 2002, D: July 2002

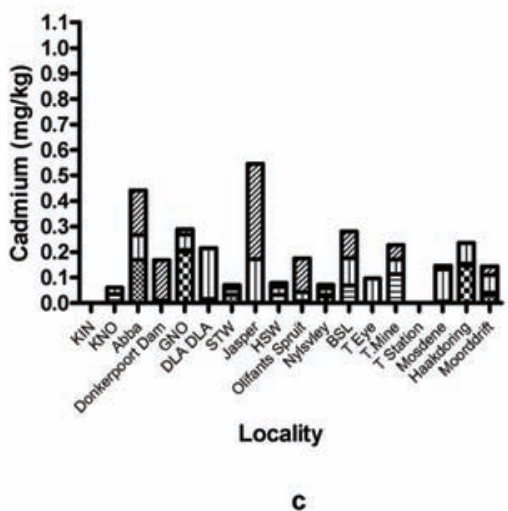

b

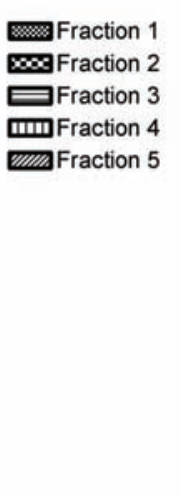

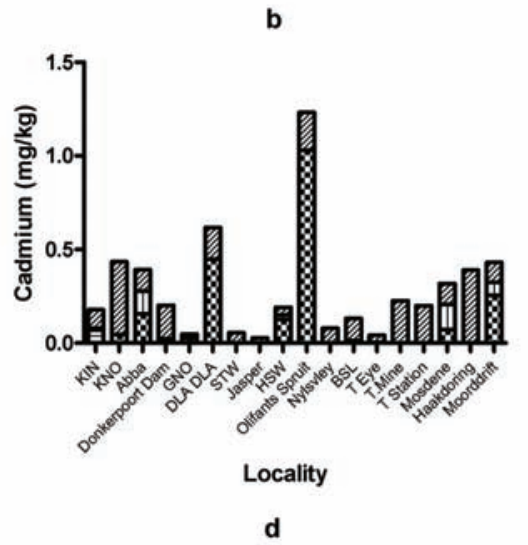

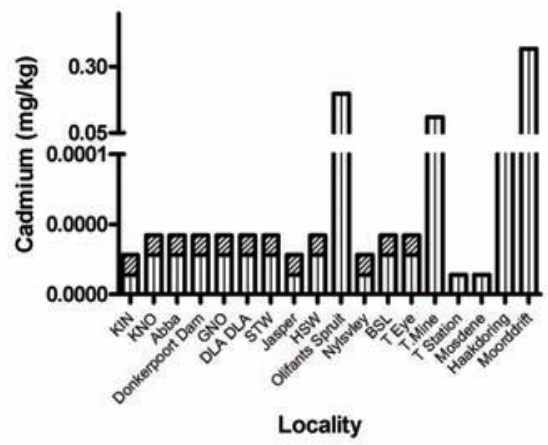

Figure 9(a-d)

Cadmium concentrations $(\mathrm{mg} / \mathrm{kg}$ ) in the different fractions during the different sampling months. A: August 2001, B: November 2001, C: March 2002, D: July 2002 generally fell below or at the lower end of the SQG range (34 to $270 \mathrm{mg} / \mathrm{kg}$ ) with one exception. An excessively high copper concentration $(786.5 \mathrm{mg} / \mathrm{kg}$ ) was recorded at the source of the Klein Nyl River (KNO) during July 2002 (Fig. 7 D). This level was found in the $2^{\text {nd }}$ fraction, which would indicate that copper is readily available. The site is, however, situated on a farm about $50 \mathrm{~m}$ from the source of the Klein $\mathrm{Nyl}$ River so it can be assumed the levels come from natural sources.

A comparison between the corresponding fractions from each sampling month indicated that Fraction 3 was the only fraction that exhibited significant differences. Significant differences in mean copper concentration were between November 2001 and July 2002, and March 2002 and July 2002.

\section{Arsenic}

Arsenic is a highly toxic metalloid element (Rodrigues et al., 2003; Pizzaro et al., 2003). It is widely distributed as a trace element in rocks and soils and is mainly mobilised by microbial activities (Garcia-Sanchez and AlvarezAyuso, 2003).

Figure 8 indicates the arsenic concentrations in the system during the sampling period. The graphs indicate that most of the arsenic is concentrated in the residual or inert fraction (Fraction $5)$.

Fractions 1 and 5 were the only fractions to show significant differences between sampling months. Concentrations in Fraction 1 were significantly different for August 2001 and July 2002. Fraction 5 showed a significant difference between November 2001 and March 2002.

\section{Cadmium}

Cadmium is a non-essential trace element that enters the 
environment via anthropogenic activities such as sewage-sludge, fertilisers and pesticides (DWAF, 1996). Cadmium adsorbs strongly to sediments and organic matter (Sanders et al., 1999). Cadmium has a range of negative physiological effects on a organism, such as decreased growth rates and negative effects on embryonic development (Newman and McIntosh, 1991)

Figure 9 indicates the cadmium concentrations recorded during the sampling period.

The maximum cadmium concentration of $2.5 \mathrm{mg} / \mathrm{kg}$ recorded during sampling fell within the SQG and thus cadmium poses little potential threat to the organisms in the system. No differences were recorded between corresponding fractions for each month with the exception of Fraction 4, where significant differences were found between November 2001 and March 2002 and November 2001 and July 2002.

\section{Lead}

Lead is a non-essential trace element (Ewers and Schlipkoter, 1991). The toxicity of lead is dependent on the life stage of the organism, and the presence of organic material (Hellawell, 1986). Decreases in water $\mathrm{pH}$ can increase the bioavailability of lead in the system (Hellawell, 1986).

Figure 10 indicates lead concentrations determined in the system during the sampling period. The results indicate that the majority of the lead is partitioned in Fractions 3, 4 and 5 .

No significant differences were noted in mean lead concentrations between corresponding fractions for Fraction 2 and 3 from August 2001 to July 2002. In Fraction 1 significant differences were recorded between August 2001 and March 2001, August 2001 and July 2002, November 2001 and March 2001 and November 2001 and July 2002. In Fraction 5 significant differences were recorded between August 2001 and November 2001, March 2002 and July 2002,
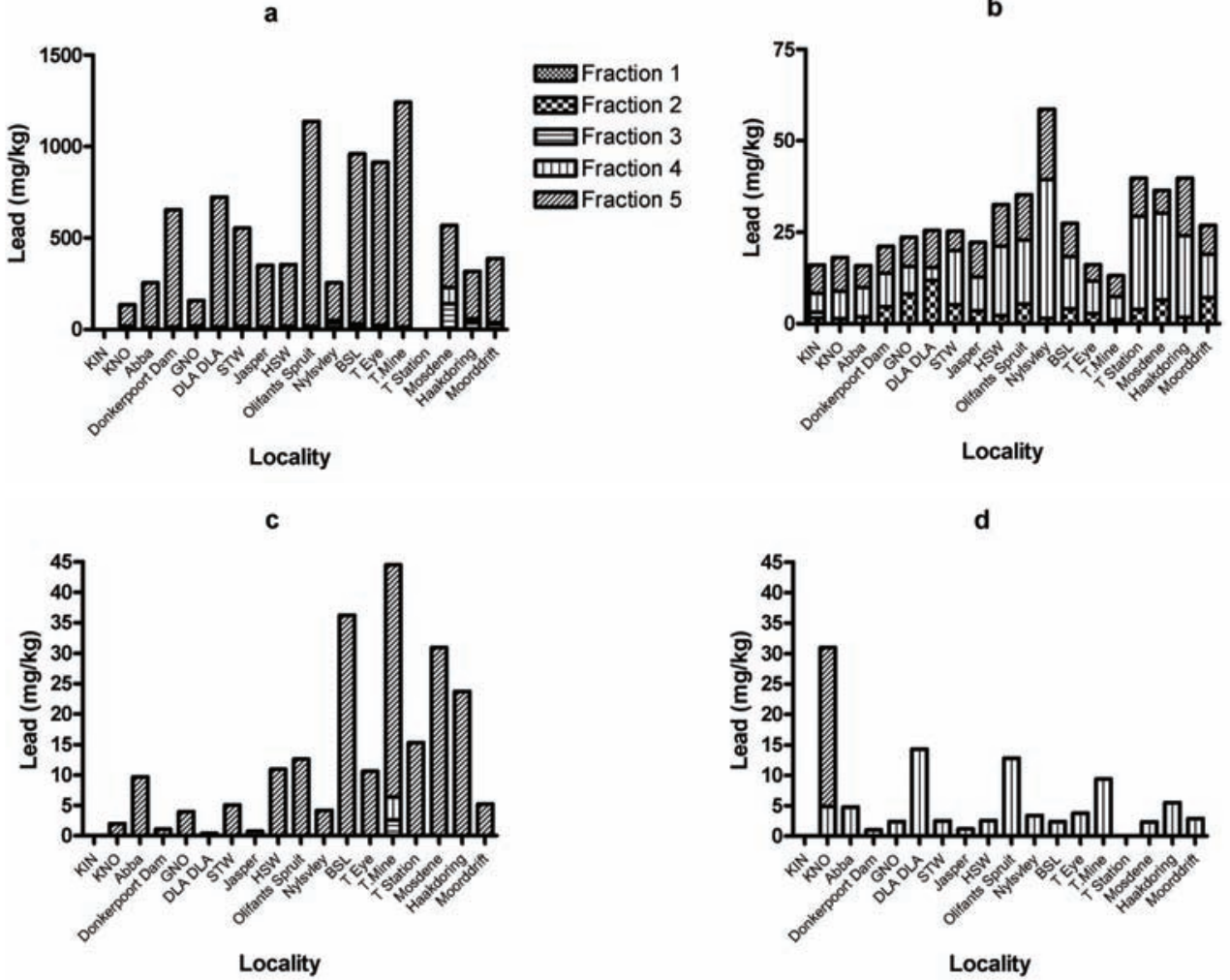

Figure 10(a-d)

Lead concentrations $(\mathrm{mg} / \mathrm{kg})$ in the different fractions during the different sampling months. A: August 2001, B: November 2001, C: March 2002, D: July 2002 a

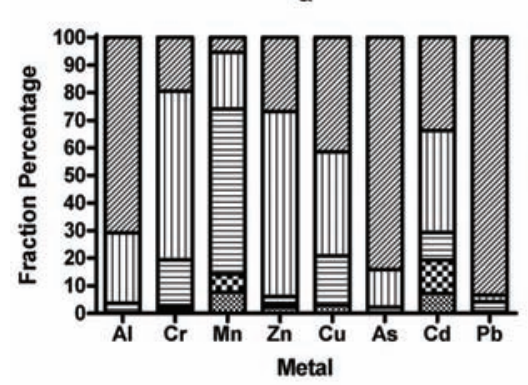

c

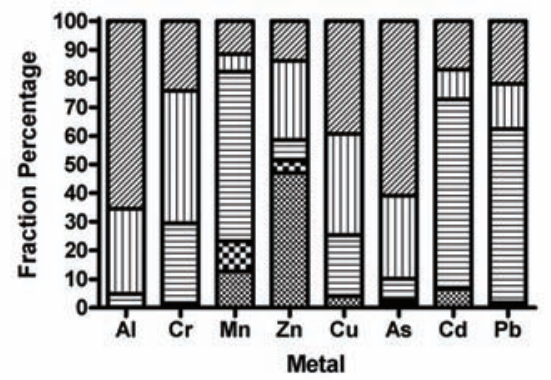

b

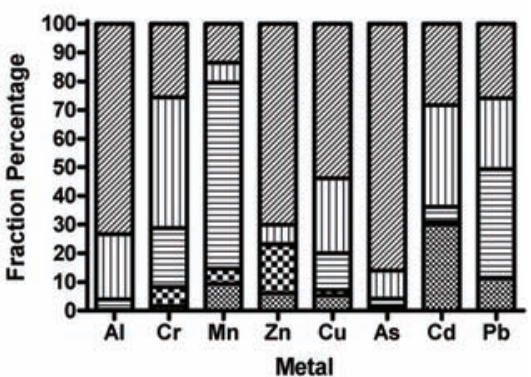

d

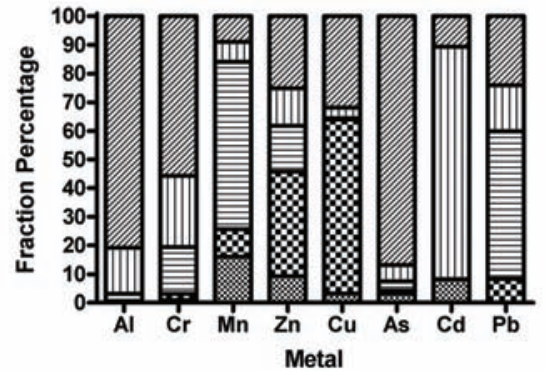

Figure 11 (a-d)

Fraction percentage of mean metal concentrations
November 2001 and March 2002 and November 2001 and July 2002.

All lead concentrations fell within the SQG range except for Fraction 5 in August 2001. This is little cause for concern as Fraction 5 is the residual/inert fraction and the lead would thus be from geogenic origin. 


\section{Conclusions}

The results clearly indicate that the metals do not appear to pose an environmental problem in the system. Figures $11 \mathrm{~A}$ to D indicate a stacked graph of the percentage makeup of the different fractions for the different metals. The figure indicates that the majority of the metals are partitioned into Fractions 3, 4 and 5 are generally not bioavailable. This would signify that metals from the sediments pose little to no potential threat to the organisms in the system. This would also imply that most of the metals in the system are from a natural source.

The results also indicate that all metal concentrations fell within the lower end of the Sediment Quality Guideline Range. These will thus have little or no effect on the organisms in the system. Zinc was the only metal that had concentrations greater than the guideline value. This is however little cause for concern as they were recorded in the residual or inert fraction (Fraction $5)$. This would imply that they are natural concentrations in the sediment.

\section{Acknowledgements}

The authors would like to thank the staff at the University of Johannesburg for logistical support provided for the study. The Water Research Commission is thanked for funding and valuable advice.

\section{References}

ANON (2003a) Lets Go -South Africa- Nylstroom (Modimolle) http:// www.letsgo.com/SAF/08-NorthernProvince-21.

ANON (2003b) Routes Travel Info Portal: Mokopane. http://www. routes.co.za/lp/mokopane

ANON (2003c) Routes Travel Info Portal: Mookgopong. http://www. routes.co.za/lp/mookgopong.

ANON (2003d) Explanation of the metallogenic map sheet 2428. http:// www.geoscience.org.za/whatsnew/nylstroom.htm .

ANON (2007) Friends of the Vley and Nyl Floodplain. World locator map. http://www.nylsvley.co.za/worldlocatormap

BUYKX SEJ, VAN DEN HOOP MAGT and LOCH JPG (2002) Dissolution kinetics of heavy metals in Dutch carbonate and sulphide-rich freshwater sediments. J. Environ. Qual. 31 573-580.

COETZEE P (1993) Determination and speciation of heavy metals in sediments of the Hartbeespoort Dam by sequential chemical extraction. Water SA 19 (4) 291-300.

DEPARTMENT OF WATER AFFAIRS AND FORESTRY (DWAF) (1996) South African Water Quality Guidelines Volume 7: Aquatic Ecosystems. 159 pp.

ENVIRONMENTAL PROTECTION AGENCY (EPA) (1999) Sediment Quality Guidelines developed for the national status and trends program. Report No. 6/12/99. http://www.epa.gov/waterscience/cs/ pubs.htm (Accessed in May 2004).

EWERS U and SCHLIPKOTER HW (1991) Lead. In: E Merian (ed.) Metals and Their Compounds in the Environment, Occurrence, Analysis and Biological Relevance. Wiley-VCH, Weinheim. 1438 pp.

FYTIANOS K and LOURANTOU A (2004) Speciation of elements in sediment samples collected at lakes Volvi and Koronia, N. Greece. Environ. Int. 30 11-17.

GARCIA-SANCHEZ A and ALVAREZ-AYUSO E (2003) Arsenic in soils and water and its relation to geology and mining activities (Salamanca Province, Spain). J. Geol. Explor. 80 69-79.
GIBBS R, WATSON L, KOEKEMOER M, SMOOK NP, ANDERSON HM and DALLWITZ MJ (1991) Grasses of Southern Africa. Memoirs of the Botanical Survey of South Africa. No. 58.

GOMEZ ARIZA JL, GIRÁLDEZ I, SÁNCHEZ-RODAS D and MORALES E (2000) Comparison of the feasibility of three extraction procedures for trace metal partitioning in sediments from south west Spain. Sci. Total Environ. 246 271-283.

GROSELL MH, HOGSTRAND C and WOOD CM (1997) Copper uptake and turnover in both copper acclimated and non-acclimated rainbow trout (Oncorhynchus mykiss). Aquat. Toxicol. 38 257-276.

HEALTH AND WELFARE CANADA (1980) Guidelines for Canadian drinking Water Quality 1978. Supporting Documentation. Supply and Services Canada, Hull.

HELLAWELL JM (1986) Biological Indicators of Freshwater Pollution and Environmental Management. Elsevier Applied Science Publishers Ltd., London. pp. 546.

JAIN CK (2004) Metal fractionation study on bed sediments of River Yamuna, India. Water Res. 38 569-578.

KLAVINS M, RODINOV V and VERESKUNS G (1998) Metal and organochlorine compounds in fish from Latvian lakes. Bull. Environ. Contam. Toxicol. 60 538-545.

LESCHBER R, DAVIS RD and L'HERMITE P (1985) Chemical Methods for Assessing Bio-Available Metals in Sludge and Soils. Elsevier, London. $96 \mathrm{pp}$.

LI X, COLES BJ, RAMSEY MH and THORNTON I (1995) Sequential extraction of soils for multi-element analysis by ICP-AES. Chem Geol. 124 109-123.

MESTER Z, CREMISINI C, GHIARA E and MORABITO R (1998) Comparison of two sequential extraction procedures for metal fractionation in sediment samples. Anal. Chim. Acta 359 133-142.

NEWMAN MC and McINTOSH AW (1991) Metal Ecotoxicology: Concepts and Applications. Lewis Publishing, Michigan. 399 pp.

NGIAM L and LIM P (2001) Speciation patterns of heavy metals in tropical estuarine anoxic and oxidized sediments by different sequential extraction schemes. Sci. Total Environ. 275 (1-3) 53-61.

PIZZARO I , GOMEZ M, CAMARA C and PALACIOS MA (2003) Arsenic speciation in environmental and biological samples Extraction and stability studies. Anal. Chim. Acta 495 85-98.

RODRIGUEZ VM, JIMENEZ-CAPDEVILLE ME, and GIORDANO M (2003) The effects of arsenic exposure on the nervous system. Toxicol. Lett. 145 1-18.

SANDERS MJ, DU PREEZ HH and VAN VUREN JHJ (1999) Monitoring cadmium and zinc contamination in freshwater systems with the use of the freshwater crab, Potamanautius warrenii. Water SA 25 (1) 91-98. http://www.wrc.org.za/archives/watersa\%20archive/1999/ January/jan99_p91.pdf

SHINE J (2004) Biogeochemical control of heavy metal speciation and bioavailability in contaminated marine sediments. http://es.epa. gov/ncer/early/proj/earcar5.html

SUTHERLAND RA and TACK FMG (2003) Fractionation of $\mathrm{Cu}, \mathrm{Pb}$ and $\mathrm{Zn}$ in certified reference soils SRM 2710 and SRM 2711 using the optimized BCR sequential extraction procedure. Adv. Environ. Res. 8 37-50.

TACK FMG and VERLOO M G (1995) Chemical speciation and fractionation in soil and sediment heavy metal analysis: a review. Int. J. Environ. Anal. Chem. 59 225-238.

TARBOTON WR (1987) The Nyl River floodplain. Fauna \& Flora 45.

TESSIER A, CAMPBELL PGC and BISON M (1979) Sequential extraction procedure for speciation of particulate trace metals. Anal. Chem. 51 844-851.

ULBRICH K, MARSULA R, JELTSCH F, HOFMANN H and WISSEL C (1997) Modelling the ecological impact of contaminated river sediments on wetlands. Ecol. Model. 94 221-230. 